\title{
Phylogenetics, Safety and In Vitro Functional Properties of Bacillus Species Isolated from Iru, a Nigerian Fermented Condiment
}

\author{
Gbenga Adedeji Adewumi ${ }^{1,2}$, Sunita Grover ${ }^{2}$, Chukwuemeka Isanbor ${ }^{3}$, and Folarin Anthony Oguntoyinbo ${ }^{1 *}$ \\ ${ }^{1}$ Department of Microbiology, Faculty of Science, University of Lagos, Akoka, Lagos 03005, Nigeria \\ ${ }_{2}^{2}$ Molecular Biology Unit, Dairy Microbiology Division, ICAR-National Dairy Research Institute, Karnal-132001 (Haryana), India \\ ${ }^{3}$ Department of Chemistry, Faculty of Science, University of Lagos, Akoka, Lagos 03005, Nigeria
}

Received: March 8, 2019 / Revised: June 1, 2019 / Accepted: June 3, 2019

\begin{abstract}
Bacillus species were isolated from iru, a traditional fermented condiment in Nigeria. Polyphasic approach was used to evaluate the phylogenetic relationship and strain sub-type of the isolated species. Additionally, the phylogenetic profiles of the species isolated from iru were compared with those of bacilli isolated from different continents. The phylogenetic diversity analysis was performed using the combination of $16 \mathrm{~S}$ rRNA gene sequencing, ITS-PCR, ITS-PCR-RFLP, and M13 RAPD-PCR. The analysis revealed that Bacillus subtilis $\mathrm{U} 170 \mathrm{~B}$ and $B$. subtilis $\mathrm{U} 146 \mathrm{~A}$ isolated from $i r u$ were the closest relatives of strains belonging to the phylogeny of $B$. subtilis sensu stricto and were related to other bacilli isolated from different continents that had functional benefits. The two isolated species exhibited resistance to acidic $\mathrm{pH}$ (pH 2.0). The survival rates of B. subtilis U170B, B. subtilis U146A, and B. clausii UBBC-07 (commercial probiotic strain) cultured at $\mathrm{pH} 2.0$ for $3 \mathrm{~h}$ were $33.45,12.44$, and $9.53 \%$, respectively. The strains were highly tolerant to bile salts $[0.3 \%(\mathrm{w} / \mathrm{v})]$. B. subtilis U170B exhibited the highest cell viability (43.45\%) when cultured for $3 \mathrm{~h}$ in the presence of bile salts, followed by B. subtilis U146A (25\%) and B. clausii UBBC-07 (18.94\%). B. subtilis U170B and B. subtilis U146A did not exhibit haemolytic activity and were susceptible to different antibiotics. Additionally, these two strains exhibited weak antagonistic activity against $B$. cereus. The diverse wild strains of $B$. subtilis can be used as a safe multifunctional starter culture for the industrial production of condiments with health benefits.
\end{abstract}

Keywords: Beneficial, Bacillus subtilis, fermentation, antimicrobial, phylogenetic

\section{Introduction}

Parkia biglobosa (Jacq. Benth) cotyledons are naturally fermented to produce iru or daddawa, a traditional alkaline food condiment, consumed by over ca. 150 million human populations in West Africa [1]. Similar alkaline fermented vegetable protein foods in Asia, produced mainly from soybeans [Glycine $\max (\mathrm{L}$.)] include natto

\section{*Corresponding author}

Tel: +234805 47 48166, Fax: +2348054748166

E-mail: foguntoyinbo@unilag.edu.ng

๑) 2019, The Korean Society for Microbiology and Biotechnology
[2], thua nao [3], kinema [4] and tungrymbai [5]. Production process of iru as well as similar products has been previously described [6], it involves enzymatic and biochemical changes, enhanced by the environmental microbes, raw materials, fermentation vessel and processors, resulting into competitive adaptation and activities of autochthonous, spoilage and pathogenic microorganisms.

Bacillus subtilis has been repeatedly reported as the dominant bacterium responsible for the fermentation of leguminous vegetable protein seeds during condiments production in Africa [7-9]. Recently, we used culture- 
independent molecular method to support this information and confirmed the presence of potential food-borne bacterial pathogens and contaminants, such as Staphylococcus saprophyticus, B. thuringiensis, Morganella morganii, Salinicoccus jeotgali and Tetragenococcus halophilus during natural fermentation of $P$. biglobosa to produce iru [10]. This information further reinforced the need to develop a controlled and sustainable fermentation system, by using multifunctional starter cultures that can initiate fermentation, dominate the process and rapidly ferment the substrate, for improved nutritional benefits, safety and quality, as well as determination of functions that can impart human gut health, especially when fermentation bacteria are consumed in large populations.

Furthermore, Bacillus strains used as probiotics for human consumption are allochthonous; they are not normal microbiota of the human gastrointestinal tract (GIT), but have been described as bacteria with frequent transient in the gut, and their endospores when consumed in large populations in fermented vegetal protein seeds could germinate and proliferate to establish adhesion and colonization for probiotic functions [11]. Germination of Bacillus spores in the GIT of chickens, mice and pigs, and adaptation to intestinal ecosystems as part of their natural life cycle is well documented [1214]. B. coagulans MTCC 5856 in LactoSpore ${ }^{\circledR}$, a probiotic product, strongly adhered to human colonic cells HT-29 and LS174T, for colonization of the intestinal mucosal surfaces [15].

Bacilli exist as both vegetative and stable endospores after fermentation of the legumes during iru production. They are transmitted with iru to the GIT, and the beneficial functional properties of bacilli strains in the gut has been shown in other studies [16]. Here, we determined the genetic diversity of bacilli strains in fermented vegetable protein legume seeds, $P$. biglobosa, and preliminarily demonstrated their potential properties that can enable their consideration for selection as multifunctional strains both as starter cultures and possible gut health beneficial candidates for use in resource limited countries.

\section{Materials and Methods}

\section{Bacterial strains}

B. subtilis $\mathrm{U} 170 \mathrm{~B}$ and B. subtilis $\mathrm{U} 146 \mathrm{~A}$ (NCBI acces- sion numbers: JN255720 and JN255713 respectively) were previously isolated from iru in Nigeria [17], and deposited in the culture collection of the Department of Microbiology, University of Lagos, Nigeria. B. clausii UBBC-07 (MTCC 5472), a probiotic reference strain was kindly provided by Unique Biotechnology Limited, Hyderabad, India. B. subtilis MTCC 2451 and B. cereus MTCC 430 (Microbial Type Culture Collection and Gene Bank, India), Lactobacillus sakei DSM $20017^{\mathrm{T}}$, L. casei DSM $20011^{\mathrm{T}}$ (Deutsche Sammlung von Mikroorganismen und Zellkulturen, DSMZ, Germany). S. aureus subsp. aureus ATCC 11632, Escherichia coli ATCC 11229, Listeria monocytogenes ATCC 19118 and Enterococcus faecium ATCC 35667 were obtained from American Type Culture Collection (ATCC), USA. B. cereus MBU 1011, S. aureus MBU 1023, E. coli MBU 1035 and Salmonella enterica serovar Typhimurium MBU 1047 were from in-house culture collection of National Dairy Research Institute (NDRI), Karnal, India. Bacillus strains were routinely maintained on nutrient agar (HiMedia, India); lactobacilli and E. faecium ATCC 35667 were cultured on MRS agar (Merck, Germany). Other bacterial cultures were grown on BHI agar (HiMedia).

\section{Genomic DNA extraction}

Genomic DNA of Bacillus strains were extracted according to the method previously described by Jeyaram et al. [18], with some modifications by overnight suspension of extracted DNA in $10 \mathrm{mM}$ Tris at $\mathrm{pH}$ 8.0. DNA quantity and purity were determined at $260 \mathrm{~nm}$ using 2000ND NanoDrop spectrophotometer (Thermo Scientific, USA).

\section{Bacillus species characterization and strains sub-typing}

Wild bacilli isolated from iru, type and reference strains were included in the internal transcribed spacer (ITS) PCR, ITS-PCR-restriction fragment length polymorphism (ITS-PCR-RFLP) and randomly amplified polymorphic DNA (RAPD-PCR) analysis. The procedure involved using DNA extracted from the bacteria for PCR amplification and conditions [19,20] were based on 16Sf-R2 and 23Sr-R10 primers for ITS-PCR and M13 primer for RAPD-PCR (Table 1), including digestion of the ITS-PCR amplified products with $C f o \mathrm{I}$ as previously described [17]. The gel profiles of ITS-PCR, ITS-PCR- 
Table 1. List of PCR primers used in this study.

\begin{tabular}{clcc}
\hline Primer names & \multicolumn{1}{c}{ Primer sequences } & Target regions & References \\
\hline fD1 & 5'-AGAGTTTGATCCTGGCTCAG-3' & 16S rRNA & $\begin{array}{c}\text { Weisburg et al. (1991); } \\
\text { Escalante et al. (2007) }\end{array}$ \\
rD1 & 5'-AAGGAGGTGATCCAGCCGCA-3" & This study \\
M13 & 5'-GAGGGTGGCGGTTCT-3' & ra & Lechner et al. (1998) \\
16Sf-R2 & 5'-CGCGGGATCCTTGTACACACCGCCCGTC-3' & 16S-23S rRNA & \\
23Sr-R10 & 5'-GGCCGTCGACCCTTTCCCTCACGGTACTG-3' & & \\
\hline
\end{tabular}

ra: Random amplification.

RFLP and RAPD-PCR polymorphisms were analyzed using NTSYSpc. 2.20e [22] for the generation of clusters in a dendrogram, based on Jaccard similarity coefficient $\left(\mathrm{S}_{\mathrm{J}}\right)$ and unweighted pair group method using arithmetic averages (UPGMA).

\section{PCR amplification of 16S rRNA gene and phylogenetic analysis}

The 16S rRNA gene $c a .1500 \mathrm{bp}$ of representative Bacillus strains within the formed clusters of ITS-PCR, ITS-PCR-RFLP and RAPD-PCR was amplified with the universal primers pair fD1 and rD1 (Table 1). PCR master mixture contained $2.0 \mu \mathrm{l}$ of $50 \mathrm{ng}$ template DNA, $2.5 \mu \mathrm{l}$ of $1 \mathrm{X}$ PCR reaction buffer with $1.5 \mathrm{mM} \mathrm{MgCl}_{2}$, $1.0 \mu \mathrm{l}$ of $1.0 \mathrm{mM} \mathrm{MgCl} 2,0.2 \mu \mathrm{l}$ of $0.8 \mu \mathrm{M}$ each of forward and reverse primers, $0.2 \mu \mathrm{l}$ of $200 \mu \mathrm{M}$ each of the dNTPs, $0.5 \mu \mathrm{l}$ of $1.5 \mathrm{U}$ Taq DNA polymerase (Sigma-Aldrich), and made up to $25 \mu \mathrm{l}$ with $18.4 \mu \mathrm{l}$ sterile deionized water. Amplification was performed in a master cycler (Eppendorf 5333, USA), with cycling steps as described in Table 1. PCR amplified products were checked in $0.8 \%$ agarose (Promega, USA) containing ethidium bromide (EtBr; $0.5 \mu \mathrm{g} / \mathrm{ml}$ ) (Sigma-Aldrich), using $1 \mathrm{~kb}$ DNA ladder (Promega) as a molecular weight standard, in an electrophoretic condition of $80 \mathrm{~V}$ for $1.5 \mathrm{~h}$. Sequencing reactions were prepared using primers $08 \mathrm{~F} / 1391 \mathrm{R}$ and the BigDye Terminator v3.1 Cycle Sequence Kit (Applied Biosystems, USA) according to the manufacturer's guidelines. Reactions were analyzed with an ABI 3730xl analyzer (Applied Biosystems). Forward and reverse reads were manually checked and then assembled into a contiguous sequence using the SeqMan (DNASTAR Inc., USA). The nearly full-length 16S rRNA gene sequences obtained were compared against those deposited in GenBank database BLAST program, to determine closest known relatives, and also for identification purpose. Sequences that showed more than $97 \%$ similarity were considered to belonging to the same species [23]. Phylogenetic and molecular evolutionary analysis based on pairwise and multiple alignments of consensus 16S rRNA gene sequences of Bacillus strains from iru, type and reference, including commercially available probiotic Bacillus strains were conducted using MEGA7 software (www.megasoftware.net) [29].

\section{In vitro examinations of Bacillus strains for tolerance of gut conditions}

\section{Acid resistance and bile salts tolerance.}

Bacillus vegetative cells and spores resistance to simulated gastric juice (SGJ) of the stomach and simulated intestinal fluid (SIF) of the small intestine were assayed as described by Duc et al. [30] with some modifications. Bacillus spores were previously induced and prepared in Difco Sporulating Medium (DSM) using modified nutrient exhaustion method of Nicholson and Setlow [31]. Spores were thereafter stained and observed under phase contrast microscope (BX61, Olympus, Japan). Both vegetative cells and spores were suspended in $0.85 \% \mathrm{NaCl}, \mathrm{pH}$ 2.0 containing $1 \mathrm{mg} / \mathrm{ml}$ pepsin (Sigma-Aldrich, UK), and isotonic buffer [Bott and Wilson salts: $\mathrm{K}_{2} \mathrm{HPO}_{4}-1.24 \%$; $\mathrm{KH}_{2} \mathrm{PO}_{4}-0.76 \%$; tri-Sodium citrate-0.1\%; $\left(\mathrm{NH}_{4}\right)_{2} \mathrm{SO}_{4}$ $0.6 \%, \mathrm{pH} 6.7$ ] containing $0.3 \%(\mathrm{w} / \mathrm{v})$ bile salts concentration (HiMedia, India) and $1 \mathrm{mg} / \mathrm{ml}$ pancreatin (SigmaAldrich, USA) for acid resistance and bile salts tolerance respectively. Aliquots were immediately taken after 1, 2, and $3 \mathrm{~h}$ of incubation, respectively at $37^{\circ} \mathrm{C}$ with agitation, and subsequently after a longer incubation period of $24 \mathrm{~h}$. Appropriate serial dilutions of suspensions were plated in replicate to determine cells and spores counts on nutrient and DSM agar respectively. 
Antimicrobial activity of Bacillus strains against foodborne pathogens. Production of antimicrobial substances by Bacillus strains against closely related species of organisms or genera, including food-borne pathogens $(L$. sakei DSM 20017 ${ }^{\mathrm{T}}$, L. casei DSM 20011 ${ }^{\mathrm{T}}$, S. aureus subsp. aureus ATCC 11632, E. coli ATCC 11229, L. monocytogenes ATCC 19118, E. faecium ATCC 35667, B. cereus MTCC 430, B. cereus MBU 1011, S. aureus MBU 1023, E. coli MBU 1035 and S. enterica serovar Typhimurium MBU 1047) was determined using two methods; the agar spot-on-lawn test as described by Schillinger and Lücke [32] and the colony overlay assay by Pugsley [33], as well as the agar well diffusion assay using cell-free supernatant as earlier described [34].

\section{Safety assessment studies}

Haemolysis on blood agar. Bacillus strains (B. subtilis U170B, B. subtilis U146A, B. clausii UBBC-07, B. cereus U175 and a reference haemolytic B. cereus MBU 1011) grown in nutrient broth (HiMedia) for $18 \mathrm{~h}$ at $37^{\circ} \mathrm{C}$ were streaked on BHI agar, supplemented with 5\% sheep blood, and incubated at $37^{\circ} \mathrm{C}$ for $18-24 \mathrm{~h}$. A $\beta$-haemo- lytic activity is indicated by the presence of clear zone around the streaked area (positive), $\alpha$-haemolysis is associated with partial clearance zone and greenish colouration around the streaked region, while ( $\gamma$-haemolysis) is without clearance zone, which is considered negative [35].

Antibiotic susceptibility testing. The susceptibility of Bacillus strains to antibiotics was determined by modification of the standard disk and agar overlay diffusion methods of Clinical and Laboratory Standards Institute [36]. Antibiotic disks analyzed include: penicillin G (P, 10 units/disk), ampicillin (AMP, $10 \mu \mathrm{g} /$ disk) ( $\beta$-lactams); erythromycin (E, $15 \mu \mathrm{g} /$ disk), vancomycin (VA, $30 \mu \mathrm{g} /$ disk) (Gram+ve spectrum); nalidixic acid (NA, $30 \mu \mathrm{g} /$ disk) (Gram-ve spectrum); chloramphenicol (C, $30 \mu \mathrm{g} /$ disk), rifampicin (RIF, $5 \mu \mathrm{g} /$ disk), tetracycline (TE, $30 \mu \mathrm{g} /$ disk) (broad spectrum); kanamycin (K, $30 \mu \mathrm{g} /$ disk), gentamicin (GEN, $10 \mu \mathrm{g} /$ disk), streptomycin ( $\mathrm{S}, 10 \mu \mathrm{g} /$ disk) (aminoglycosides); others were amoxyclav (AMC, $30 \mu \mathrm{g} /$ disk), clindamycin (CD, $2 \mu \mathrm{g} /$ disk), ciprofloxacin (CIP, $5 \mu \mathrm{g} /$ disk), methicillin (MET, $5 \mu \mathrm{g} /$ disk), trimetho-

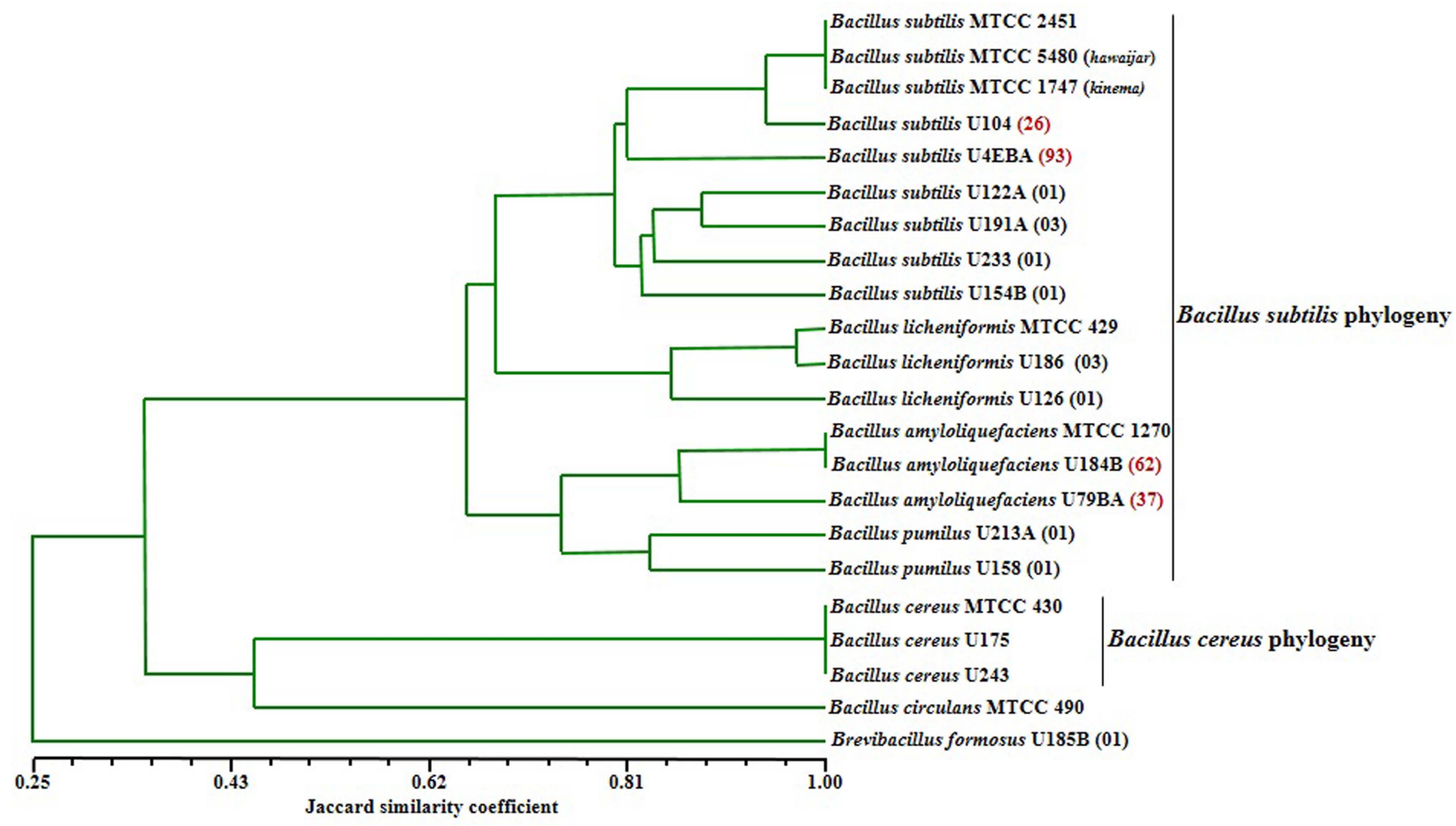

Fig. 1. Dendrogram based on UPGMA clustering of Jaccard similarity coefficient (Sj) of normalized combined ITS-PCR and ITS-PCR-RFLP fingerprint patterns of Bacillus species isolated from iru and reference strains. 
prim (TR, $5 \mu \mathrm{g} /$ disk) and norfloxacin (NX, $10 \mu \mathrm{g} /$ disk). Already prepared BHI agar plates were overlaid with soft BHI agar (0.7\%), containing $100 \mu \mathrm{l}$ of bacterial isolates at log phase growth. After solidification, the antibiotic disks (HiMedia) were aseptically placed onto the agar surface, and plates were incubated at $37^{\circ} \mathrm{C}$ for $18-$ $24 \mathrm{~h}$, to allow for bacterial-antibiotic interaction. Diameters of zones of inhibition in two replicate, including those of the disks (in $\mathrm{mm}$ ) were measured and the results were expressed in terms of resistance $(R)$ and susceptibility (S) in accordance to Performance Standards for Antimicrobial Disk Susceptibility Tests, CLSI.

\section{Results}

\section{Characterization and 16S rRNA gene phylogenetic of Bacillus species}

Results of the combined dendrogram of ITS-PCR and ITS-PCR-RFLP characterized different species of bacilli as diverse. Fig. 1 shows two major clusters identified as B. subtilis and the B. cereus phylogeny. However, analysis of the ITS-PCR-RFLP further shows that B. subtilis phylogeny is comprised of three sub-clusters that include strains of species identified as B. licheniformis, B. amyloliquefaciens and B. pumilus. Further analysis using RAPD-PCR indicated high strains genomic divergence and sub-types among the wild $B$. subtilis sensu stricto strains in iru (Fig. 2). These B. subtilis strains were grouped into three major sub-clusters, while the $B$. subtilis MTCC 2451 did not cluster with any of the groups (Fig. 2). Phylogenetic tree constructed using 16S rRNA gene sequences identified seven different clusters (Fig. 3). Cluster I indicated evolutionary relatedness and clonal relationship among $B$. subtilis strains from iru, $B$. subtilis subsp. inaquosorum DSM $22148^{\mathrm{T}}$, B. subtilis subsp. spizizenii DSM 6405 ${ }^{\mathrm{T}}$, B. subtilis subsp. subtilis DSM $10^{\mathrm{T}}$ and $B$. subtilis ATCC 9799 type strains, including one commercial Bacillus probiotic product (Lactipan Plus). Biosubtyl is the only member of cluster II, which is a sub-group of cluster I at bootstrap value $>80 \%$. Cluster III consists of two B. cereus probiotic strains, marketed as Biosubtyl-Dala and Bactisubtil in Asia and Europe respectively. The fourth cluster comprises of closely related strains of $B$. alcalophilus, present in registered probiotic product (Domuvar) and $B$.

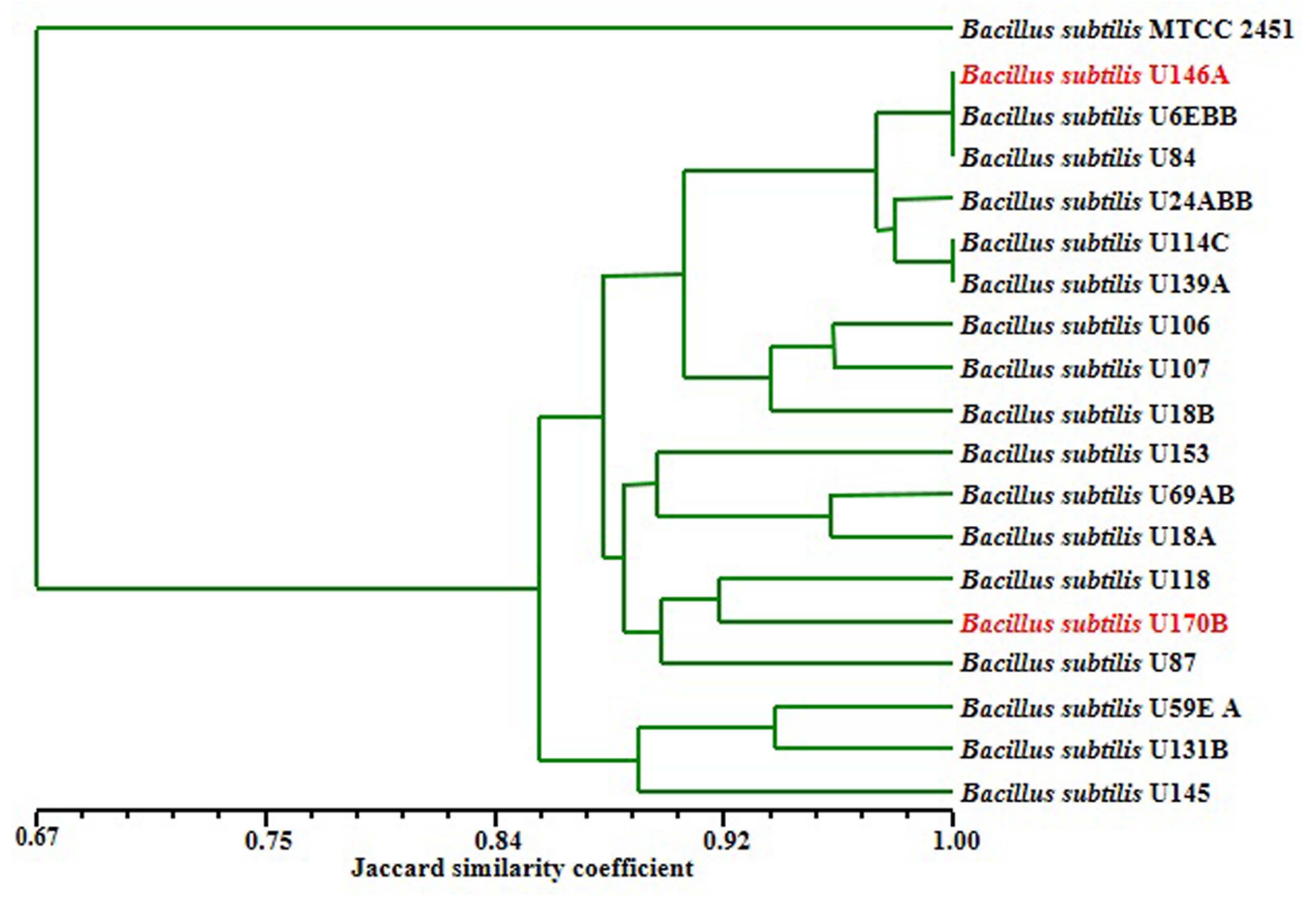

Fig. 2. Dendrogram based on UPGMA clustering of Jaccard similarity coefficient (Sj) of normalized ITS-PCR, ITS-PCRRFLP M13 RAPD-PCR finger-prints of divergent $B$. subtilis strains. 


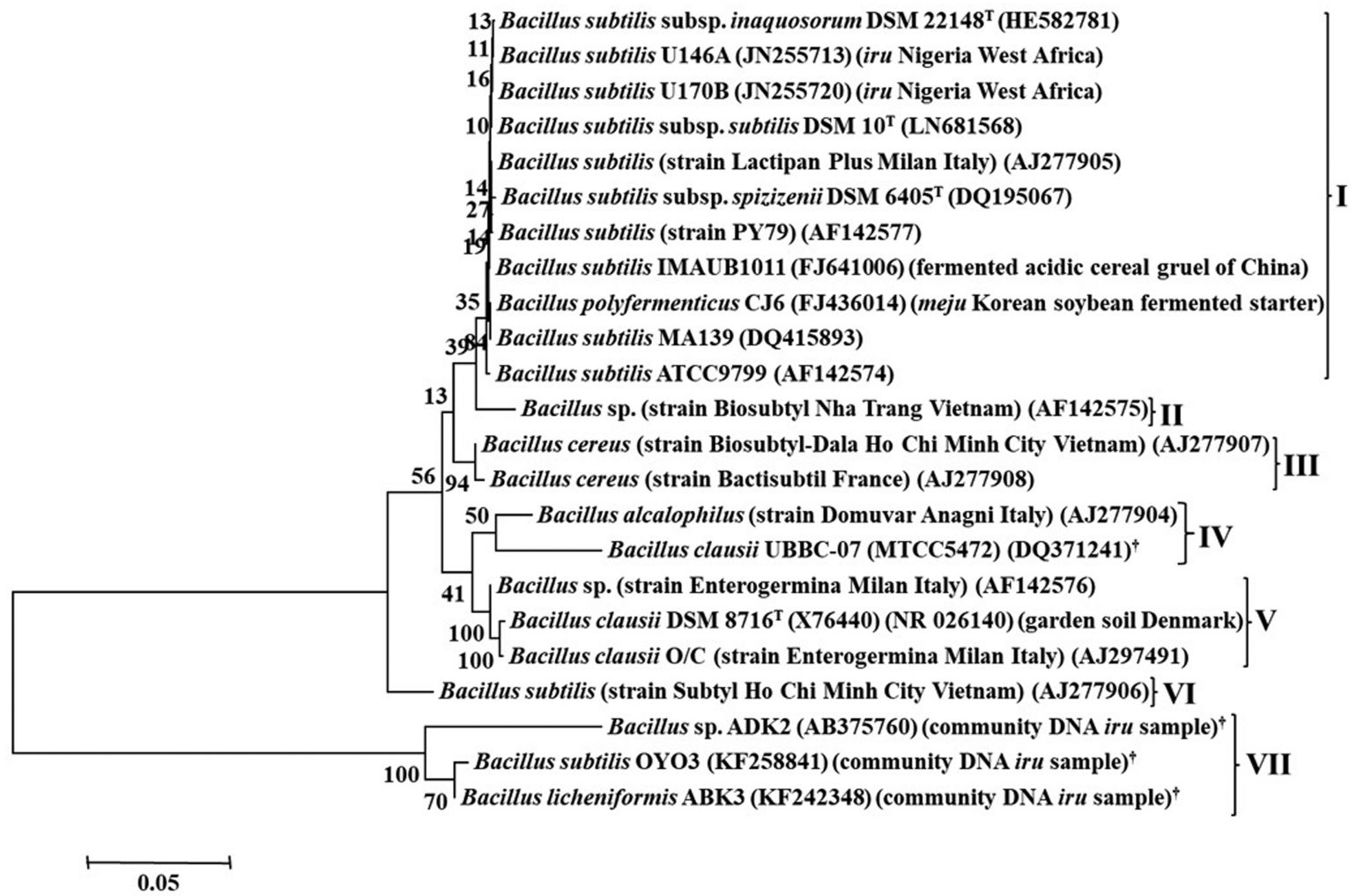

Fig. 3. Phylogenetic tree of pairwise and multiple alignments of 16S rRNA gene sequences of Bacillus strains isolated from iru, type, reference, and commercial probiotic Bacillus products. The tree was generated using the Molecular Evolutionary Genetics Analysis (MEGA7) software. ${ }^{\dagger}$ Accession no. of closest relative organisms of nucleotide sequences found in GenBank database.

clausii probiotic reference strain. Cluster V has Bacillus sp. and B. clausii in Enterogermina probiotic products, in addition to $B$. clausii DSM $8716^{\mathrm{T}}$. B. subtilis Subtyl is also the only strain in cluster VI, while the last cluster comprises of Bacillus strains from bacterial community DNA analysis of iru samples.

\section{In vitro probiotic functional properties of Bacillus strains Resistance to acid and tolerance to bile salts. Vegetative} cells of bacilli analyzed generally showed resistance to acid condition of $\mathrm{pH} 2.0$ at $37^{\circ} \mathrm{C}$. B. subtilis $\mathrm{U} 170 \mathrm{~B}$ and $B$. clausii UBBC-07 (a probiotic reference strain obtained from India) had just $<1$ Log unit reduction after $3 \mathrm{~h}$ incubation, while B. subtilis U146A had 1 Log unit lower (Fig. 4A). The survival rates (expressed in percentage) of the Bacillus strains based on initial viable colony counts and population counts after $3 \mathrm{~h}$ incubation at $37^{\circ} \mathrm{C}$ were $33.45 \%, 12.44 \%$ and $9.53 \%$ for B. subtilis U170B, B. clausii UBBC-07, and B. subtilis U146A, respectively.
Longer incubation up to $24 \mathrm{~h}$ did not show resistance but rather cell death. The three strains exhibited higher tolerance to bile salts concentration of $0.3 \%(\mathrm{w} / \mathrm{v})$, compared to their resistance to acidic $\mathrm{pH}$. In terms of Log cycle loss, they all had $<1$ Log unit reduction (Fig. 4B). Cell viability of these strains after $3 \mathrm{~h}$ passage in bile salts was also higher compared to that of gastric juice. $B$. subtilis $\mathrm{U} 170 \mathrm{~B}$ demonstrated the highest survival rate (43.45\%), followed by B. subtilis U146A (25.00\%) and B. clausii UBBC-07 (18.94\%). In general, vegetative cells of B. subtilis $\mathrm{U} 170 \mathrm{~B}$ were more acid-resistant and bile salts-tolerant than the other two strains tested. However, only B. clausii UBBC-07 spores survived the acidic and bile salts conditions; others were found to be highly sensitive as no single spore count was recorded. The $B$. clausii UBBC-07 spores thrived in both low $\mathrm{pH}$ and bile salts with an average marginal decrease of 0.5 Log cycle losses (Fig. 4C). Survival rates obtained were $42.27 \%$ and $20.80 \%$ for acid and bile salts respectively. 

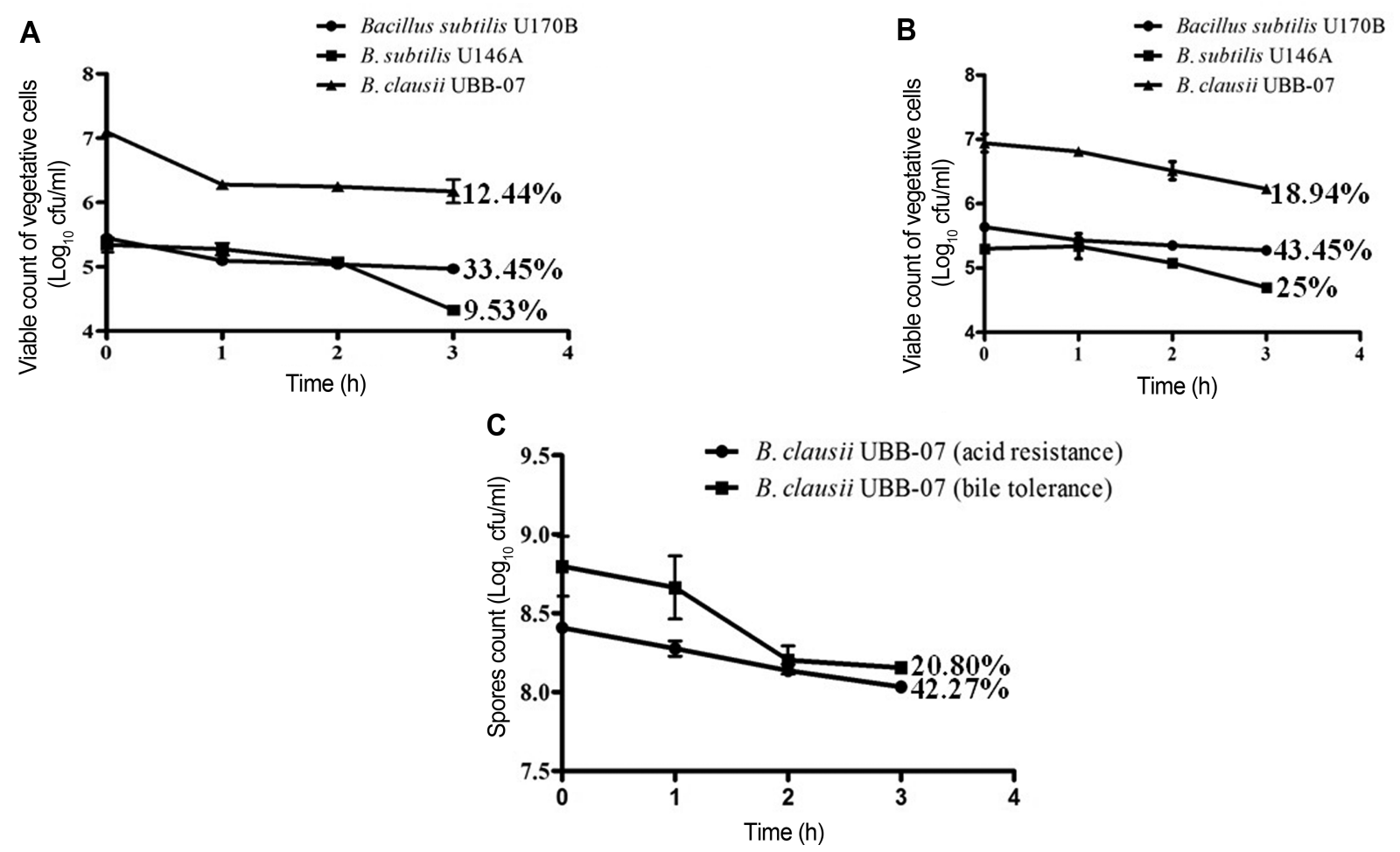

Fig. 4. Growth and viability of Bacillus strains under simulated gastric juice and intestinal bile conditions. (A) Acid resistance and (B) bile resistance of vegetative cells of $B$. subtilis strains from iru and B. clausii UBB-07 reference probiotic strain; (C) acid and bile tolerance of $B$. clausii UBB-07 spores. Error bars represent the standard deviation of replicate determinations.

In vitro antagonistic potentials of Bacillus strains against food-borne pathogens. The production of antibacterial compounds by Bacillus strains against eleven indicator bacterial strains was demonstrated. The bacilli tested could not inhibit most of the indicator organisms (Table 2). However, B. subtilis U170B and B. subtilis U146A

Table 2. Antagonistic activities of B. subtilis strains isolated from iru and reference probiotic B. clausii UBBC-07 against eleven indicator bacterial strains.

\begin{tabular}{|c|c|c|c|}
\hline \multirow{2}{*}{ Indicator strains } & \multicolumn{3}{|c|}{ Test organisms } \\
\hline & B. subtilis U170B & B. subtilis U146A & B. clausii UBBC-07 \\
\hline L. sakei DSM 20017 & - & - & nd \\
\hline L. casei DSM 20011 & - & - & nd \\
\hline S. aureus subsp. aureus ATCC 11632 & - & - & nd \\
\hline E. coli ATCC 11229 & - & - & nd \\
\hline L. monocytogenes ATCC 19118 & - & - & nd \\
\hline E. faecium ATCC 35667 & - & - & nd \\
\hline B. cereus MTCC 430 & $+(2 \mathrm{~mm})^{\mathrm{b}}$ & - & nd \\
\hline B. cereus MBU 1011 & $+(2 \mathrm{~mm})^{\mathrm{b}}$ & $+(4 \mathrm{~mm})^{\mathrm{b}}$ & $+(9 \mathrm{~mm})^{\mathrm{c}}$ \\
\hline S. aureus MBU 1023 & - & - & - \\
\hline E. coli MBU 1035 & - & - & - \\
\hline S. enterica serovar Typhimurium MBU 1047 & - & - & - \\
\hline
\end{tabular}

aDS: Deutsche Sammlung von Mikroorganismen Gottingen, Germany; ATCC: American Type Culture Collection; MTCC: Microbial

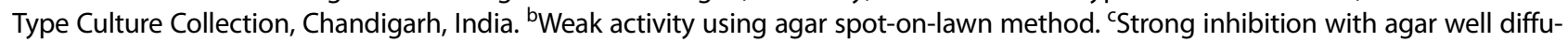
sion assay. nd: not determined. Diameter of inhibition zone obtained after subtracting diameter of bored hole from the entire halo. 
Table 3. Type of haemolysis on blood agar.

\begin{tabular}{lccc}
\hline & Alpha & Beta & Gamma \\
\hline B. subtilis U170B & - & - & + \\
B. subtilis U146A & - & - & + \\
B. clausii UBBC-07 & + & - & - \\
B. cereus U175 & - & + & - \\
\hline
\end{tabular}

showed weak inhibition zone against $B$. cereus MTCC 430 and $B$. cereus MBU 1011 with the agar spot-on-lawn method. No zone of inhibition was detected using the cell-free supernatant of these strains. B. clausii UBBC07 displayed strong antimicrobial activity against $B$. cereus MBU 1011 (Table 2), though wider inhibitory zone was recorded for agar spot-on-lawn.

\section{In vitro safety evaluation of Bacillus strains Haemolytic activity.}

B. subtilis strains U170B and U146A isolated from iru did not lyse red blood cells when streaked on BHI agar containing sheep blood. This can be considered $\gamma$-haemolytic. B. clausii UBBC-07 had $\alpha$-haemolysis with partial clearance zone and greenish colouration around the region streaked. $B$. cereus U175 also from iru and hae- molytic B. cereus MBU 1011 used as positive controls produced complete clear zones, indicating $\beta$-haemolysis (Table 3).

Antibiotic susceptibility pattern. B. subtilis $\mathrm{U} 170 \mathrm{~B}$ and B. subtilis U146A were sensitive to most of the antibiotics; however, the latter was resistant to methicillin (Table 4). On the contrary, B. clausii UBBC-07 was resistant to majority of the antibiotics used, but only sensitive to chloramphenicol.

\section{Discussion}

There is dearth of information on the beneficial health potentials of Bacillus species consumed in large populations with African fermented condiments. This study first provided information about the genetic diversity of these bacilli isolated from fermented condiments in Africa, and determined in vitro properties, to enable selection of multifunctional strains that can be used as starter cultures, as well as having ability to survive gut conditions. This endeavour can culminate in the use of safe strains with dual functions, with an overall objective of improving gut health beneficial properties using a

Table 4. Antibiotic sensitivity profiles of B. subtilis strains isolated from iru and reference probiotic B. clausii UBBC-07.

\begin{tabular}{llcc}
\hline \multicolumn{1}{c}{ Antibiotics (symbol, $\mu \mathrm{g})$} & & Zone of inhibition (mm) \\
\cline { 2 - 4 } & B. subtilis U170B & B. subtilis U146A & B. clausii UBB-07 \\
\hline Kanamycin (K, 30) & $25.10 \pm 0.28^{\dagger}(\mathrm{S})$ & $27.40 \pm 0.71(\mathrm{~S})$ & $16.35 \pm 0.07(\mathrm{I})$ \\
Amoxyclav (AMC, 30) & $37.15 \pm 0.92(\mathrm{~S})$ & $40.00 \pm 0.85(\mathrm{~S})$ & $3.20 \pm 0.99(\mathrm{R})$ \\
Ampicillin (AMP, 10) & $24.10 \pm 0.14(\mathrm{~S})$ & $26.20 \pm 0.14(\mathrm{~S})$ & $1.40 \pm 0.57(\mathrm{R})$ \\
Chloramphenicol (C, 30) & $25.15 \pm 0.07(\mathrm{~S})$ & $29.30 \pm 0.28(\mathrm{~S})$ & $25.00 \pm 0.99(\mathrm{~S})$ \\
Clindamycin (CD, 2) & $19.10 \pm 0.14(\mathrm{~S})$ & $34.25 \pm 0.35(\mathrm{~S})$ & $11.25 \pm 0.78(\mathrm{R})$ \\
Ciprofloxacin (CIP, 5) & $33.15 \pm 0.35(\mathrm{~S})$ & $38.15 \pm 0.78(\mathrm{~S})$ & $14.25 \pm 0.50(\mathrm{R})$ \\
Erythromycin (E, 15) & $23.10 \pm 0.42(\mathrm{~S})$ & $42.25 \pm 0.07(\mathrm{~S})$ & $10.05 \pm 0.21(\mathrm{R})$ \\
Gentamicin (GEN, 10) & $27.20 \pm 0.28(\mathrm{~S})$ & $24.15 \pm 0.35(\mathrm{~S})$ & $13.15 \pm 0.07(\mathrm{I})$ \\
Methicillin (MET, 5) & $10.00 \pm 0.28(\mathrm{I})$ & $4.20 \pm 0.99(\mathrm{R})$ & $-(\mathrm{R})$ \\
Nalidixic Acid (NA, 30) & $15.05 \pm 0.35(\mathrm{I})$ & $28.35 \pm 0.21(\mathrm{~S})$ & $5.25 \pm 0.35(\mathrm{R})$ \\
Penicillin G (P, 10 units) & $39.20 \pm 0.57(\mathrm{~S})$ & $34.35 \pm 0.35(\mathrm{~S})$ & $-(\mathrm{R})$ \\
Rifampicin (RIF, 5) & $24.20 \pm 0.28(\mathrm{~S})$ & $25.45 \pm 0.35(\mathrm{~S})$ & $5.25 \pm 0.50(\mathrm{R})$ \\
Streptomycin (S, 10) & $23.10 \pm 0.57(\mathrm{~S})$ & $29.05 \pm 1.20(\mathrm{~S})$ & $12.20 \pm 0.14(\mathrm{I})$ \\
Tetracycline (TE, 30) & $38.30 \pm 0.71(\mathrm{~S})$ & $34.30 \pm 0.28(\mathrm{~S})$ & $5.05 \pm 1.06(\mathrm{R})$ \\
Trimethoprim (TR, 5) & $24.20 \pm 0.14(\mathrm{~S})$ & $24.15 \pm 0.64(\mathrm{~S})$ & $-(\mathrm{R})$ \\
Vancomycin (VA, 30) & $22.00 \pm 1.13(\mathrm{~S})$ & $28.60 \pm 0.14(\mathrm{~S})$ & $12.10 \pm 1.13(\mathrm{R})$ \\
Norfloxacin (NX, 10) & $36.05 \pm 0.50(\mathrm{~S})$ & $32.35 \pm 0.21(\mathrm{~S})$ & $11.60 \pm 0.42(\mathrm{R})$ \\
\hline
\end{tabular}

${ }^{\ddagger}$ Values have antibiotic disk $(6 \mathrm{~mm})$ subtracted from them. ${ }^{\dagger}$ Mean with standard deviation (SD) of two replicate data. S, sensitive; I, intermediate; $\mathrm{R}$, resistant as per CLSI. 
sustainable food fermentation strategy.

The results of the phylogenetic analysis confirmed the genetic diversity among wild bacilli strains associated with fermentation of iru in Nigeria. The strains shows similarities with their closest relatives isolated from other regions of the world. The dominance of $B$. subtilis during fermentation of condiments in W. Africa has been very consistent. In this study, the ITS-PCR, ITS-PCRRFLP and RAPD-PCR data is in agreement with many previous studies on the prevalence and diversity of $B$. subtilis in fermented condiments; similar report was reported for soumbala in Burkina Faso and okpehe in Nigeria [7, 37]. RAPD-PCR data showed a clear strain divergence among the wild $B$. subtilis isolated from fermented iru in Nigeria, and divergence such as this has been linked to horizontal gene transfer and homologous recombination that is very common with bacteria in different ecosystems [38]. The maintenance of gene diversification and genome stability is also attributed to diversity in functional properties of bacilli, as mediated by the change in the composition of gene coding for different phenotypic traits. Similarly, 16S rRNA gene phylogenetic method has been used consistently in earlier studies to depict bacilli phylogeny in food. Oguntoyinbo et al. [37] differentiated strains of bacilli isolated from okpehe, a fermented Prosopis africana seeds. In another study, Meerak et al. [39] used the same method to compare bacilli isolated from fermented condiment in Ghana with those obtained from Japanese natto. The 16S rRNA gene data in this study shows similarity among the closest Bacillus relatives of iru, food-borne wild strains of $B$. subtilis that originated from different regions of the world, and furthermore confirmed that strains U146A and U170B that were selected as potential starter cultures, with ability to survive gut conditions belong to the B. subtilis sensu stricto, with a clear distinction from other Bacillus species.

The Bacillus strains tested for survival under simulated stomach conditions, consisting of pepsin and $\mathrm{pH}$ adjusted to 2.0 maintained satisfactory cell viability and adaptation at human body temperature $\left(37^{\circ} \mathrm{C}\right)$ for $3 \mathrm{~h}$, with maximum of 1 Log cfu reduction. This insignificant loss in viable cells indicates the potential resistance of these strains to the acidic condition normally encountered during transit in the stomach. The resistant nature of vegetative cells of $B$. subtilis DSM $5750^{\mathrm{T}}$ and
B. licheniformis DSM $5749^{\mathrm{T}}$ in BioPlus ${ }^{\circledR} 2 \mathrm{~B}$, a probiotic product, to simulated human gastric juice of $\mathrm{pH} 2.2$ has also been reported [40], with a survival rate of $9 \%$; the least being recorded in the present study. In the simulated small intestinal fluid of $0.3 \%(\mathrm{w} / \mathrm{v})$ bile salts concentration, the Bacillus strains demonstrated marginal decrease in the final Log counts of vegetative cells and persisted after $3 \mathrm{~h}$, with greater percentage survival rates compared to the SGJ condition. Similarly, Zhang et al. [41] reported higher cell viability and $<1$ Log cycle loss of lactobacilli strains when challenged for $4 \mathrm{~h}$ in pancreatin solution ( $\mathrm{pH} 8.0$ ) and $0.3 \%$ bile salts compared to SGJ. In addition, B. licheniformis LS-1, the putative probiotic culture in white shrimp aquaculture also displayed high bile salt tolerance, in relation to its viability and resistance to simulated gastric fluid (SGF) [42]. Spore suspensions of the two B. subtilis strains from iru unfortunately were acutely susceptible to the simulated gut conditions, whereas $B$. clausii UBBC-07 spores remained viable. The plausible reason for this may be that as frequently analyzed laboratory strains, these bacteria must have lost one or more of their natural traits, which would have been responsible for persistence of spores within the GIT. Previously, Bacillus probiotic products carrying spores exhibited very high sensitivity to SGJ and SIF [30].

In the antagonistic activity assay against food-borne pathogens, B. subtilis $\mathrm{U} 170 \mathrm{~B}$ and B. subtilis U146A fairly inhibited B. cereus MTCC 430 and B. cereus MBU 1011 , closely related bacterial species, known to cause diarrhoeal and emetic food poisoning, while B. clausii UBBC-07 showed stronger inhibitory spectrum on solid agar medium. Probiotic B. pumilus and B. licheniformis strains from seaweed earlier produced weak antimicrobial activity against food-borne pathogens [40]. None of the two B. subtilis strains produced inhibitory zone in the cell-free culture supernatants (CFCS), whereas $B$. clausii UBBC-07 demonstrated antagonism under same test conditions. The reason for this may be due to the fact that the supernatants were crude in nature, not concentrated, as was done in previous studies [8, 32]; hence the negative results obtained do not necessarily mean that an antimicrobial compound was not produced. Toure et al. [43] earlier reported failure of un-concentrated supernatants of bifidobacteria to produce inhibition against target organisms, which was recovered 
when concentrated.

Bacilli in iru were non-haemolytic whereas commercial strain B. clausii UBBC-07 displayed partial haemolysis. They were also sensitive to most of the common clinically important antibiotics, suggesting that these organisms can be safely used as starter cultures for human consumption, as well as potential probiotic. $B$. subtilis consumed in large counts in alkaline fermented condiments in the W. African sub-region and Asian subcontinent has long history of safe use. To this end it was ascribed GRAS status by FDA and included in the inventory of Microbial Food Culture (MFC) by the International Dairy Federation, and also given a Qualified Presumption of Safety (QPS) by the European Food Safety Authority (EFSA) [44]. B. clausii UBBC-07 was however resistant to virtually all the antibiotics analyzed. Enterogermina ${ }^{\circledR}$ B. clausii was earlier found to be resistant to a number of antibiotics [45, 46]. Although, this organism is marketed as a commercial probiotic product, a more detailed safety examination is pertinent. It would be important to check for the presence of transferable plasmids and mobile genetic elements linked with antibiotic resistance, since strains harbouring transmissible antibiotic resistance genes are not suitable for use as probiotics [47]. On the overall, two divergent wild $B$. subtilis strains isolated from iru demonstrated preliminary and promising in vitro properties that could be further studied to enable their selection as potential starter cultures with probiotic beneficial functions. The combination of genome analyses enabled identification of $B$. subtilis U146A to be genetically distinct from B. subtilis U170B, an information requiring further functional gut health beneficial studies.

\section{Acknowledgments}

Folarin A. Oguntoyinbo and Chukwuemeka Isanbor were funded by Mini Grant of the Central Research Committee, (CRC), University of Lagos. We deeply appreciate the kind efforts of Namita Rokana and Hogarehalli Mallapa Rashmi during the period of this research at NDRI, Karnal, India. Unique Biotechnology Limited, Hyderabad, India kindly provided B. clausii UBBC-07 (MTCC 5472) probiotic reference strain. Gbenga Adedeji Adewumi (GAA) is a recipient of INSA JRD-TATA research training fellowship. The short-term study leave granted to GAA by University of Lagos, Nigeria that facilitated his collaboration with NDRI, is gratefully acknowledged.

\section{Conflict of Interest}

The authors have no financial conflicts of interest to declare.

\section{References}

1. Odunfa SA. 1986. Dawadawa. In Reddy NR, Pierson MD, Salunkhe DK (eds.), pp. 173-189. Legume-based Fermented Foods. CRC Press, Boca Raton, Florida.

2. Kubo $Y$, Rooney AP, Tsukakoshi $Y$, Nakagawa $Y$, Hasegawa $H$, Kimura K. 2011. Phylogenetic analysis of Bacillus subtilis strains applicable to natto (fermented soybean) production. Appl. Environ. Microbiol. 77: 6463-6469.

3. Leejeerajumnean A, Duckham SC, Owens DJ, Ames JM. 2001. Volatile compounds in Bacillus-fermented soybeans. J. Sci. Food Agric. 81: 525-529.

4. Dahal NR, Karki TB, Swamylingappa B, Li Q, Gu GX. 2005. Traditional foods and beverages of Nepal: a review. Food Rev. Int. 21: 1-25.

5. Chettri R, Tamang JP. 2015. Bacillus species isolated from tungrymbai and bekang, naturally fermented soybean foods of India. Int. J. Food Microbiol. 197: 72-76.

6. Odunfa SA, Oyewole OB. 1998. African fermented foods. pp. 712752. In Wood BJB (ed.), Microbiology of Fermented Foods, 2nd Ed. Vol. 2. Blackie Academic and Professional, London, UK.

7. Ouoba LII, Diawara B, Amoa-Awua WK, Traore AS, Møller PL. 2004. Genotyping of starter cultures of Bacillus subtilis and Bacillus pumilus for fermentation of African locust bean (Parkia biglobosa) to produce Soumbala. Int. J. Food Microbiol. 90: 197-205.

8. Oguntoyinbo FA, Sanni Al, Franz CMAP, Holzapfel WH. 2007. In vitro selection and evaluation of Bacillus strains as starter cultures for the production of okpehe, a traditional African fermented condiment. Int. J. Food Microbiol. 113: 208-218.

9. Ademola OM, Adeyemi TE, Ezeokoli OT, Ayeni Kl, Obadina AO, Somorin YM, et al. 2018. Phylogenetic analyses of bacteria associated with the processing of iru and ogiri condiments. Lett. Appl. Microbiol. 67: 354-362.

10. Adewumi GA, Oguntoyinbo FA, Keisam S, Romi W, Jeyaram K. 2013. Combination of culture-independent and culture-dependent molecular methods for the determination of bacterial community of iru, a fermented Parkia biglobosa seeds. Front. Microbiol. 3: 436.

11. Sorokulova IB, Pinchuk IV, Denayrolles M, Osipova IG, Huang JM, Cutting SM, et al. 2008. The safety of two Bacillus probiotic strains for human use. Dig. Dis. Sci. 53: 954-963.

12. Tam NKM, Uyen NQ, Hong HA, Duc LH, Hoa TT, Serra CR, et al. 2006. The intestinal life cycle of Bacillus subtilis and close relatives. J. Bacteriol. 188: 2692-2700.

13. Cartman ST, La Ragione RM, Woodward MJ. 2008. Bacillus subtilis spores germinate in the chicken gastrointestinal tract. Appl. Environ. Microbiol. 74: 5254-5258.

14. Leser TD, Knarreborg A, Worm J. 2008. Germination and outgrowth of Bacillus subtilis and Bacillus licheniformis spores in the 
gastrointestinal tract of pigs. J. Appl. Microbiol. 104: 1025-1033.

15. Shinde T, Vemuri R, Shastri MD, Perera AP, Tristram S, Stanley R, et al. 2019. Probiotic Bacillus coagulans MTCC 5856 spores exhibit excellent in-vitro functional efficacy in simulated gastric survival, mucosal adhesion and immunomodulation.J. Funct. Foods 52: 100108.

16. Cutting SM. 2011. Bacillus probiotics. Food Microbiol. 28: 214-220.

17. Adewumi GA, Oguntoyinbo FA, Romi W, Singh TA, Jeyaram K. 2014. Genome sub-typing of autochthonous Bacillus species isolated from iru, a fermented Parkia biglobosa seeds. Food Biotechnol. 28: $250-268$.

18. Jeyaram K, Romi W, Singh TA, Adewumi GA, Basanti K, Oguntoyinbo FA. 2011. Distinct differentiation of closely related species of Bacillus subtilis group with industrial importance. J. Microbiol. Methods. 87: 161-164.

19. Weisburg WG, Barns SM, Pelletier DA, Lane DJ. 1991. 16 S ribosomal DNA amplification for phylogenetic study. J. Bacteriol. 173: 697-703.

20. Escalante A, Wacher C, Farrés A. 2001. Lactic acid bacterial diversity in the traditional Mexican fermented dough pozol as determined by 165 rDNA sequence analysis. Int. J. Food Microbiol. 64: 21-31.

21. Lechner S, Mayr R, Francis KP, Pruss BM, Kaplan T, Wiessner-Gunkel E, et al. 1998. Bacillus weihenstephanensis sp. nov. is a new psychrotolerant species of the Bacillus cereus group. Int. J. Syst. Bacteriol. 48: $1373-1382$.

22. Rohlf FJ. 1998. NTSYSpc., 'Numerical taxonomy and multivariate analysis system, version 2.20e, Exeter Software, New York.

23. Altschul SF, Madden TL, Schaffer AA, Zhang J, Zhang Z, Miller W, et al. 1997. Gapped BLAST and PSI-BLAST: a new generation of protein database search programs. Nucleic Acids Res. 25: 3389-3402.

24. Thompson JD, Higgins DG, Gibson TJ. 1994. Clustal W: improving the sensitivity of progressive multiple sequence alignment through sequence weighting, position-specific gap penalties and weight matrix choice. Nucleic Acids Res. 22: 4673-4680.

25. Kimura M. 1980. A simple method for estimating evolutionary rates of base substitutions through comparative studies of nucleotide sequences. J. Mol. Evol. 16: 111-120.

26. Saitou N, Nei M. 1987. The neighbor-joining method: A new method for reconstructing phylogenetic trees. Mol. Biol. Evol. 4: 406-425.

27. Nei M, Kumar S. 2000. Molecular evolution and phylogenetics. New York (NY): Oxford University Press.

28. Felsenstein J. 1985. Confidence limits on phylogenies: an approach using the bootstrap. Evolution 39: 783-791.

29. Kumar S, Stecher G, Tamura K. 2016. MEGA7: Molecular evolutionary genetics analysis version 7.0 for bigger datasets. Mol. Biol. Evol. 33: 1870-1874.

30. Duc LH, Hong HA, Barbosa TM, Henriques AO, Cutting SM. 2004. Characterization of Bacillus probiotics available for human use. Appl. Environ. Microbiol. 70: 2161-2171.

31. Nicholson WL, Setlow P. 1990. Sporulation, germination and outgrowth. pp. 391-450. In Harwood CR, Cutting SM (eds.), Molecular Biological Methods for Bacillus. John Wiley \& Sons Limited, Chichester, UK.
32. Schillinger U, Lücke FK. 1989. Antibacterial activity of Lactobacillus sake isolated from meat. Appl. Environ. Microbiol. 55: 1901-1906.

33. Pugsley AP. 1985. Escherichia coli K12 strains for use in the identification and characterization of colicins. J. Gen. Microbiol. 131: 369-376.

34. Wang $Y$, Zhang $H$, Zhang L, Liu W, Zhang $Y$, Zhang X, et al. 2010. In vitro assessment of probiotic properties of Bacillus isolated from naturally fermented congee from Inner Mongolia of China. World J. Microbiol. Biotechnol. 26: 1369-1377.

35. De Vuyst L, Foulquié Morenoa MR, Revets H. 2003. Screening for enterocins and detection of hemolysin and vancomycin resistance in enterococci of different origins. Int. J. Food Microbiol. 84: 299-318.

36. Clinical and Laboratory Standards Institute (CLSI). 2009. Performance standards for antimicrobial susceptibility testing: Nineteenth informational supplement. pp. 149. Clinical and laboratory standards institute, Wayne.

37. Oguntoyinbo FA, Huch M, Cho G-S, Schillinger U, Holzapfel W, Sanni Al, et al. 2010. Diversity of Bacillus species isolated from okpehe, a traditional fermented soup condiment of Nigeria. J. Food Prot. 73: 870-878.

38. Fernández S, Ayora S, Alonso JC. 2000. Bacillus subtilis homologous recombination: genes and products. Res. Microbiol. 151: 481-486.

39. Meerak J, Yukphan P, Miyashita M, Sato H, Nakagawa Y, Tahara Y. 2008. Phylogeny of gamma-polyglutamic acid-producing Bacillus strains isolated from a fermented locust bean product manufactured in West Africa. J. Gen. Appl. Microbiol. 54: 159-166.

40. Prieto ML, O'Sullivan L, Tan SP, McLoughlin P, Hughes H, Gutierrez $M$, et al. 2014. In vitro assessment of marine Bacillus for use as livestock probiotics. Mar. Drugs 12: 2422-2445.

41. Zhang Y, Zhang L, Du M, Yi H, Guo C, Tuo Y, et al. 2011. Antimicrobial activity against Shigella sonnei and probiotic properties of wild lactobacilli from fermented food. Microbiol. Res. 167: 27-31.

42. Cai Y, Yuan W, Wang S, Guo W, Li A, Wu Y, et al. 2019. In vitro screening of putative probiotics and their dual beneficial effects: To white shrimp (Litopenaeus vannamei) postlarvae and to the rearing water. Aquac. 498: 61-71.

43. Toure R, Kheadr E, Lacroix C, Moroni O, Fliss I. 2003. Production of antibacterial substances by bifidobacterial isolates from infant stool active against Listeria monocytogenes. J. Appl. Microbiol. 95: 1058-1069.

44. European Food Safety Association (EFSA). 2005. Opinion of the Scientific Committee on a request from EFSA related to a generic approach to the safety assessment by EFSA of microorganisms used in feed/food and the production of feed/food additives. Euro. Food Safety Authority 226: 1-12.

45. Green DH, Wakeley PR, Page A, Barnes A, Baccigalupi L, Ricca E, et al. 1999. Characterization of two Bacillus probiotics. Appl. Environ. Microbiol. 65: 4288-4291.

46. Hoa NT, Baccigalupi L, Huxham A, Smertenko A, Van PH, Ammendola S, et al. 2000. Characterization of Bacillus species used for oral bacteriotherapy and bacterioprophylaxis of gastrointestinal disorders. Appl. Environ. Microbiol. 66: 5241-5247. 
47. Vankerckhoven V, Huys G, Vancanneyt M, Vael C, Klare I, Romond $M B$, et al. 2008. Biosafety assessment of probiotics used for human consumption: recommendations from the EU-PROSAFE project. Trends Food Sci. Technol. 19: 102-114. 